\title{
Determining Points of Convergence and Divergence in CSCL Chats
}

\author{
Mohammad Hamad Allaymoun ${ }^{1}$ and Stefan Trausan-Matu ${ }^{2}$ \\ ${ }^{1}$ AMA International University -Bahrain, Manama, Bahrain and ${ }^{2}$ Computer Science \\ Department, University Politehnica of Bucharest, Bucharest, Romania \\ alkarak1@yahoo.com
}

\begin{abstract}
Computer-Supported Collaborative Learning (CSCL) is one of the most significant achievements leading to improve teaching and learning using information technology, as it seeks to activate the student-centered learning, in which the student is the main focus of the learning process. Chat is considered one of the most important CSCL tools which are used in knowledge transfer and information exchange. In fact, chat is an ideal tool that aims to realize the collaborative principle, which allows individuals to express their ideas and opinions through educational dialogues. We propose a model that is capable of analysing the content of chats semiautomatically, in order to determine the most important threads that were discussed in CSCL sessions. To do this, it mainly relies on Bakhtin's ideas and Trausan-Matu's polyphonic model. Student dialogues are analyzed in order to determine the moments of convergence and divergence in their points of view, additionally to providing results in statistical tables and graphics. By these results, teachers can evaluate the educational dialogues in order to know whether students concur or not in their points of views. By doing so, this will help students in establishing educational strategies that can lead to an educational collaborative dialogue without stress or selfishness.
\end{abstract}

Keywords. Computer Supported Collaborative Learning, Chat Conversations, Divergence, Convergence, Individual participation, Natural Language Processing.

\section{Introduction}

The Computer-Supported Collaborative Learning (CSCL) is considered one of the most up to date tools that seek to improve education by using information technology and the advantages of the social web. It is composed of a set of tools capable of providing a collaborative learning environment, which gives learners the opportunity to discuss their ideas, as well as it ensures the existence of an interaction among learners that contribute to finding out and exchange knowledge. In addition, CSCL is considered a sort of elearning that relies on the collaborative social interaction among learners. Virtual educational groups may simulate the traditional educational groups of learners ${ }^{[1-5]}$. These virtual groups beneficiate from tools that allow exchanging information and reviewing the educational materials by using multimedia, which not only makes it easier for learners to easily understand the educational topics, but also makes teaching more interesting than traditional education. Accordingly, CSCL aims at transforming the educational system from a focus on the teacher which manages a transfer of knowledge and explaining the educational lessons, into a system that focuses on the learner to manage the educational dialogues and exchange of views. By doing so, students participate in constructing and transferring knowledge to the rest of their colleagues. As a 
result, the role of the teacher is to monitor the process of knowledge building, and may participate in it if needed ${ }^{[6]}$.

As well, the importance of CSCL for students lies in its ability to develop their mental abilities and educational skills, in developing educational scenarios in a simple manner, as well as encouraging students to an exploratory learning style and improving of dialogical skills, in addition to more selfdependence in transferring knowledge in order to make education participatory and collaborative.

Chat is one of the best and most used tools in CSCL ${ }^{[7]}$, which allows learners the possibility to be present within a technical virtual framework that largely resembles the classroom, as well as it allows students to express their views and discuss it through educational dialogues that are subject to many conditions, in a synchronized contact. On the other hand, chats effectively help in developing the individual skills of the students in transferring knowledge and also creating a collaborative learning environment that can realize independence in discussing learning materials. Collaboration is achieved in educational dialogues by involving all students in a coordinated effort to discuss an academic subject or solve a certain problem together ${ }^{[8]}$.

A CSCL environment with all its tools seeks to develop the e-learning to become a successful alternative to the conventional education. Like other tools, chat, as an important tool in CSCL, seeks to develop many skills of students such as the dialogical abilities, problem-solving, survey, planning, collaboration, accepting others' points of views, and other skills that should be available in the educational environment. In addition to the focus on the concept of self-education, which means, in other words, the focus on creating an education system capable of providing a suitable environment for students to highlight their skills in self-management and self-dependence in explaining topics of study, chat participates in the transfer of knowledge and solving problems. In general, chat allows integrating students having highest mental abilities with students with different mental abilities in order to help them understand the topics of study ${ }^{[9]}$.

The research presented in this paper is based on several ideas and theories in order to obtain numerical results that can be studied and analyzed. This helps teachers in evaluating the educational dialogues arising from CSCL chats, particularly determining the moments of convergence and divergence in the points of views. The latter requires following the students' dialogues in the chat and then extracting automatically the most important threads of ideas (concepts) discussed in the chat, relying on Bakhtin's ideas ${ }^{[10-12]}$ and Trausan-Matu's polyphonic model [3-4,13]. After that, the individual contributions of each participant are analyzed in order to determine the important threads the student discussed during all the period of chat. Finally, the results are indicated in the form of statistical tables or graphics, which help in easily determining the points of convergence and divergence between the students' points of views.

This paper presents, for exemplification of our approach, the analysis of one of the chats that have been conducted in a CSCL environment at Politehnica University of Bucharest. By the analysis results, the points of convergence and divergence are determined.

This paper presents, for exemplification of our approach, the analysis of one of the chats that have been conducted in a CSCL environment at Politehnica University of Bucharest. By the analysis results, the points 
of convergence and divergence are determined. The next section of the paper explains Bakhtin's ideas and Trausan-Matu's polyphonic model. The third section explains the concept of convergence and divergence of views in the educational dialogues, whereas the fourth section describes the mechanism of chat analysis and the tools that are used in the analysis. The fifth and sixth sections present and discuss the results of chat analysis, whether the results were in the form of graphics or statistical tables. The aim is to determine the points of convergence and divergence in the points of views within the chat. Finally, this paper ends with conclusions and references of CSCL.

\section{The Polyphonic Model}

The Russian philosopher Bakhtin (18951975) introduced the polyphonic theory in literature, which means that a texture of two or more simultaneous lines of independent voices (melodies) may occur in a text; as opposed to monologue that means that just one voice appear $^{[10-12]}$. Bakhtin stated that Dostoevsky (1896-1934) was the creator of the polyphonic novel and that he began an essentially new novelistic genre ${ }^{[10]}$. In general, polyphony refers to the variety of ideologies in the novel, which is equivalent to another concept for Bakhtin: Dialogism. Bakhtin stated that the "polyphonic novel" is similar to the "dialogic novel", whereas the opposite, rejected by Bakhtin's theory is the concept of "monologue" that refers to one single dominant ideology in the novel. This represents the concept of "monolinguism", which refers to a "one single voice novel" ${ }^{111-12]}$.

Dialogue is a mental and verbal activity that occurs among a group of participants, in which each participant tries to provide arguments and evidence that justify his (her) point of view. To do this, every participant tries to select the right words to convey his (her) ideas, in order to find out a solution for the problem or to explain a certain subject. In general, the educational dialogue enforces participants with a set of constraints that ensure a meaningful dialogue and also prevent turning their discussions into polemics.

For Bakhtin, dialogue is a significant process in the transfer and passage of ideas to others $^{[14]}$, as these ideas may consist of a set of words by which the participant tries to deliver his (her) ideas. For this reason, the participant concentrates on these words in the dialogue, which he (she) repeats during the period of debate. Therefore, Bakhtin's ideas summed up the possibility of reasoning on the most important ideas that have been discussed by tracking the most repeated words. Based on this, these repeated words reflect the ideological conflict between the participants, through which the most important threads that have been discussed by participants could be determined $^{[15]}$.

Trausan-Matu's polyphonic model mainly relied on Bakhtin's ideas in order to determine the most important threads that have been discussed among participants in the chats conducted in the CSCL environment ${ }^{[5]}$ and their inter-animations ${ }^{[3]}$. Trausan-Matu's polyphonic model was used for implementing analysis systems based on a set of techniques to analyze the content of the chat automatically and extracting the most repeated words by means of natural language processing (NLP). Based on Bakhtin's ideas, these extracted words (the most repeated words) indicate the most important threads of concepts that have been discussed in the chat and inter-animation. This enabled TrausanMatu's polyphonic model to establish a technical solution that can help teachers in determining the most important ideas discussed in the chats. This is also considered an essential referential model for many supportive applications to CSCL environment, 
which helps CSCL users in solving the problems that they may encounter ${ }^{[9]}$.

The suggested system in this paper seeks to determine the moments of convergence and divergence of the points of views within CSCL chats, by analyzing the content of the chat depending on the Trausan-Matu's polyphonic model, and then extracting the individual participations for each participant, as well as determining the important discussion threads in the chat. After that, threads that appeared in the chat's utterances are connected with each other. Finally, the system provides the results arising from the process of connecting threads between participants, by which the points of convergence and divergence of views can be determined in the CSCL chat.

\section{Convergence and Divergence}

The educational dialogues between students generally result in many points of convergence or divergence in their threads of discussion, especially when the student is a source of knowledge, as each student will focus on his thoughts, trying the convince his (her) colleagues in his (her) point of view by giving examples and evidence. It is expected that following the educational dialogues would reveal the existence of a continuous transfer of ideas among students. In sum, students may agree or disagree with these ideas. Therefore, teachers need to know the results of determining the points of convergence and divergence of views in order to assess the chat in general and the collaboration in particular.

In general, the divergence in the points of views within the educational dialogues can be seen as the process of generating different ideas, which seeks to solve a problem, and considered a good indicator of the creative performance $^{[16-17]}$. As for the convergent thinking, it is the process of extracting a better, most appropriate solutions based on the available information by referring to the stored information $^{[18]}$. Although there is a difference between the divergence and convergence of views in the process of knowledge construction and exchange, but it can be utilized to find collaborative indicators that can be analyzed, through which the teacher can find a general perception of the dialogical education. In other words, the convergence of views means that there is a link among common threads, which may be agreed upon by students in their chats. The agreement may have the form of an endorsement or approval on these threads. As for the divergence in the points of views, it is the attempt of each participant to focus on a certain thread, which is contrary to the idea of others. For this reason, it is noted from the chats that there is a difference and lack of harmony in the ideas under discussion.

The educational chat has a number of functions and processes that are seek to realize. As well, the most obvious goals of the educational chat are the transfer of knowledge, the social goal that aims to build relations among students and encourages the exchange of knowledge among students ${ }^{[19]}$. Accordingly, the process of knowledge transfer results in a number of interactive behaviors that develop the social goal of the chat, such as agreeing or disagreeing with the others' points of views. The transfer and exchange of knowledge begin within the chat by several measures, where the first one is bringing new ideas for discussion. Secondly, the negotiation phase by which that each participant seeks to explain his (her) ideas. Thirdly, it is the phase of convergence and divergence at which accepting or refusing the ideas of the student's colleagues are explored.

Determining the points of convergence and divergence of views helps to identify the extent of positive interaction in the transfer of knowledge and its acceptance among participants. This is considered a positive 
indicator to assess the collaboration within the educational chats. In addition, chats are primarily concerned with establishing an effective environment that helps in encouraging students to accept and converge with other points of views. On the contrary, educational dialogues should be away from being an arena of conflict and disagreement among students, which is a negative indicator of the students' behavior within dialogues. On the other hand, the difference in the points of views is not always considered passive, but it is sometimes considered a positive case that should exist in the educational dialogues within certain limits prescribed by teachers. Increasing the diversity of knowledge is considered among the benefits of the difference in the points of views, so that each student is encouraged to seek a new knowledge and then transfer it to his (her) colleagues by using examples and evidence, which may help the rest of students in rectifying their ideas or renewing the knowledge they have.

Determining the points of convergence and divergence in the points of views aims at developing the students' performance in their discussion in order to obtain an ideal educational dialogue, which will help teachers to develop teaching strategies that are capable of developing the dialogical skills within the chats, as well as enhancing the students' confidence by accepting the others' views without bias or being selfish ${ }^{[9]}$.

\section{The Chat Analysis System}

This section explains the mechanism of the system in analyzing the content of CSCL chat, which is based on the mechanism of chat analysis presented in a previous paper ${ }^{[9]}$, with a slight difference in how to determine the moments of convergence and divergence in the points of views. On the other hand, the system is capable of analyzing CSCL chats effectively to obtain results that can be studied. Usually, these chats are characterized by a special structure, which can be easily distinguished from the rest of texts and chats that take place on the internet, as these chats are composed of the following: The chat utterance number, the participant nickname, the text of the utterance, the number of the explicitly referenced utterance, the participant nickname in the reference and the text of the referenced utterance. The explicit reference means that the participant relies on most cases on his participation in the dialogue on other information previously provided by one of the participants or the participant himself (herself).

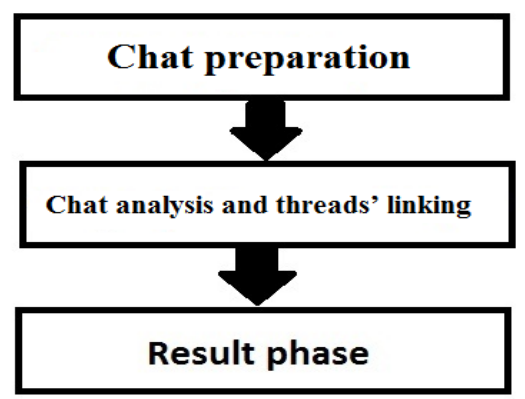

Fig. 1. Chat analysis system components.

Figure 1 illustrates the most important components of the system of the chat analysis, which are as follows:

1. Chat preparation phase: The analysis process starts by entering the chat on XML format, and then rearranging the components of the chat in a standard form, in order to facilitate the analysis process and track the participations of participants.

2. Chat analysis and threads' linking phase: The system uses NLP techniques such as tokenization, stemming and lemmatization, and stop words removing (using Stanford NLP tools - http://nlp.stanford.edu), in order to extract the most frequent words that indicate the most important threads that have been discussed. At this phase, threads are also linked with each other in order to obtain associative 
relationships, which consist of connecting any thread that appears in the text of the chat to a participant $(\mathrm{X})$ with any thread to a participant (Y).

The linking mechanism is as follows (Fig. 2):

1- Linking between threads through utterances that appear sequentially in the chat.

2- Linking between threads through explicit referencing of an utterance to another.

3. Result phase: It shows the results of analysis in the form of graphics or statistical tables, which facilitates the study and determining the points of convergence and divergence in the points of views.

\section{Determining Points of Convergence and Divergence through Individual Participants}

An educational dialogue is a process that allows the exchange and sharing of information among students. For this reason, the results will be on a participatory form of the transfer and building of knowledge. The participation would be either a convergence on certain opinions or a divergence in the points of views. Therefore, each student seeks within the chat to introduce his (her) ideas, as well as he (she) will attempt to defend his (her) point of view by reiterating these ideas along the chat, with the possibility of receiving and discussing the others' threads and ideas. According to this, teachers are always seeking to determine the most important threads that have been agreed upon, and those that have disagreed with, in order to develop teaching plans and strategies that contribute to the development of students' performance in their educational discussions, additionally to increasing the collaboration and accepting the opinions of others without exclusion or being selfish.

The system analyzes the CSCL chats in a semi-automatic way, in order to know all the important concepts, that means threads that have been discussed by the students, and then determining the threads occurrences for each participant, through extracting the number of repetitions of references for each participant to his (her) own thread. The new added value to this system is the process of linking any two threads appearing within the student's dialogue, which can be on several aspects: either in a serial form or an utterance in the chat with its reference. After that, the results of linking are represented in graphics or statistical tables. Through the linking results, the points of convergence and divergence can be easily determined in the points of views among participants.

The mechanism of analysis used by the system to determine the points of convergence and divergence depends mainly on tracking the individual participations in the chat. This means the analysis of all utterances for each participant, in order to indicate the threads mentioned in the chat and then connecting each thread that appeared in that utterances with any thread that appeared in the utterances of the chat for another participant. According to the results of linking, there are two possibilities for the process of linking threads: First, if the two threads that have been linked are identical there is a convergence of views between the participants. Second, if the two linked threads are different, it indicates that there is a divergence of views between participants.

In this research, one of the chats in the KTeams Laboratory has been used. It is chat no. 3 , the aim being to apply the system in analyzing the contents of the chat and get results that can be analyzed, and then discuss the results in order to determine the convergence and divergence points in the important threads that have been discussed among participants. One of the main reasons to use K-Teams chats in our system is that they were analyzed in a series of systems, from various perspectives ${ }^{[1,20-22]}$. 


\section{Discussions}

In this section, we will discuss the results of analyzing the chat no. 3 , in order to determine the points of convergence and divergence in the points of views. By analyzing the chat, the most frequent words were extracted from the chat, namely: forum, wave, blog, wiki and chat. They indicate the most important threads that have been discussed (which also were the associated topics to participants). Next, the system extracts the most important threads for each participant, as shown in Table 1. It should be noted from the table that the system begins to analyze the individual participations for each participant, either an utterance or the referenced utterance.

Accordingly, each utterance of a chat may have a reference, which indicates that the student is trying to link his (her) discussion to a thread that has been discussed in a previous utterance. Therefore, in order to get a more comprehensive analysis of the content of the chat, the system attempts to link the threads that have been discussed in two ways: First, between two subsequent utterances and second between a chat utterance and the utterance that reference it, if there is any.

Table 2 shows a part of the results for analyzing a chat by linking the discussed threads. The table is divided into two main parts, where the left part shows the linking between two similar threads discussed among participants. On other hand, the right part shows the linking between two different threads. The Table 2 also allows concluding several issues that help to give a general perception to the process of information exchange among participants. For example, Participant 1 discussed the subject "wave" and within the next utterance, Participant 3 discussed the same subject "wave". This indicates a convergence of views, which can be easily inferred through a discussion among two students to the same subject. On the contrary, Participant 5 discussed the subject "blog" and in the next utterance, Participant 4 discussed the subject "forum", which indicates a difference in the points of views among participants.

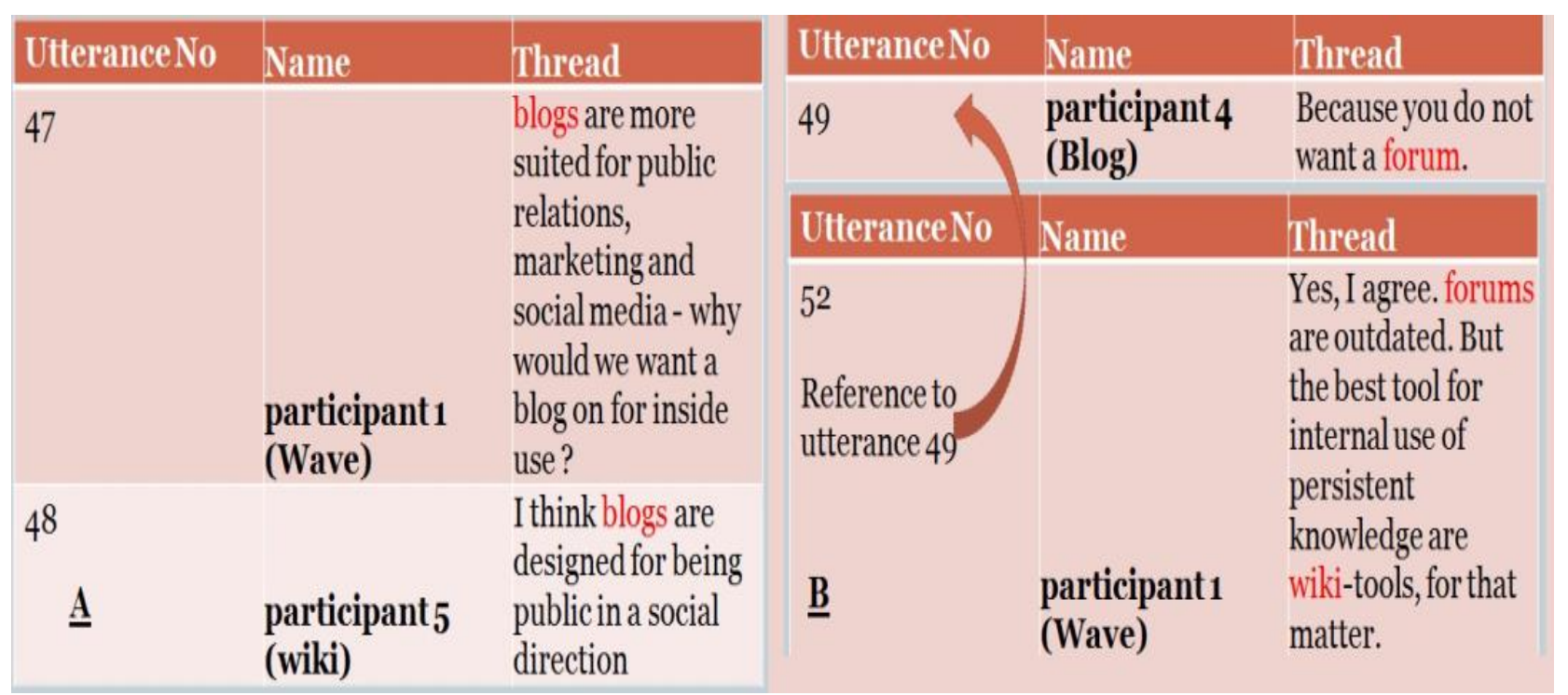

Fig. 2. a) Linking between utterance 47 and utterance 48. b) Linking between utterance 49 referenced by utterance 52. 
Table 1. Part of the Chat no.3

\begin{tabular}{|r|l|l|l|l|l|}
\hline \multicolumn{3}{|c|}{ Utterance } & \multicolumn{3}{c|}{ Referenced utterance } \\
\hline $\begin{array}{l}\text { Utterance } \\
\text { no. }\end{array}$ & $\begin{array}{l}\text { Name (own associated } \\
\text { thread) }\end{array}$ & Thread & $\begin{array}{l}\text { Referenced } \\
\text { utterance no. }\end{array}$ & $\begin{array}{l}\text { Name (own associated } \\
\text { thread) }\end{array}$ & Thread \\
\hline 16 & participant 3(Forum) & chat & 14 & participant 1(Wave) & chat \\
\hline 20 & participant 1(Wave) & wave & & & \\
\hline 21 & participant 3(Forum) & wave & & & \\
\hline 21 & participant 3(Forum) & wave & 20 & participant 1(Wave) & wave \\
\hline 22 & participant 2(Chat) & wave & 20 & participant 1(Wave) & wave \\
\hline 23 & participant 3(Forum) & chat & & & \\
\hline 24 & participant 2(Chat) & chat & & & \\
\hline 23 & participant 3(Forum) & chat & 22 & participant 2(Chat) & chat \\
\hline 24 & participant 2(Chat) & chat & 23 & participant 3(Forum) & chat \\
\hline
\end{tabular}

Table 2. The result of linking threads between participants.

\begin{tabular}{|c|c|c|c|c|c|c|c|}
\hline \multicolumn{4}{|c|}{ Links between similar threads } & \multicolumn{4}{|c|}{ Links between two different threads } \\
\hline Name & Thread & Name & Thread & Name & Thread & Name & Thread \\
\hline $\begin{array}{l}\text { participant } 1 \\
\text { (Wave) }\end{array}$ & wave & $\begin{array}{l}\text { participant } \\
3 \text { (Forum) }\end{array}$ & wave & $\begin{array}{l}\text { participant } 5 \\
\text { (wiki) }\end{array}$ & blog & $\begin{array}{l}\text { participant } 4 \\
\text { (Blog) }\end{array}$ & forum \\
\hline $\begin{array}{l}\text { participant } 3 \\
\text { (Forum) }\end{array}$ & chat & $\begin{array}{l}\text { participant } \\
2 \text { (Chat) }\end{array}$ & chat & $\begin{array}{l}\text { participant } 1 \\
\text { (Wave) }\end{array}$ & forum & $\begin{array}{l}\text { participant } 4 \\
\text { (Blog) }\end{array}$ & blog \\
\hline $\begin{array}{l}\text { participant } 1 \\
\text { (Wave) }\end{array}$ & blog & $\begin{array}{l}\text { participant } \\
5 \text { (wiki) }\end{array}$ & blog & $\begin{array}{l}\text { participant } 4 \\
\text { (Blog) }\end{array}$ & blog & $\begin{array}{l}\text { participant } 3 \\
\text { (Forum) }\end{array}$ & forum \\
\hline $\begin{array}{l}\text { participant } 2 \\
\text { (Chat) }\end{array}$ & blog & $\begin{array}{l}\text { participant } \\
4 \text { (Blog) }\end{array}$ & blog & $\begin{array}{l}\text { participant } 1 \\
\text { (Wave) }\end{array}$ & forum & $\begin{array}{l}\text { participant } 2 \\
\text { (Chat) }\end{array}$ & chat \\
\hline $\begin{array}{l}\text { participant } 2 \\
\text { (Chat) }\end{array}$ & blog & $\begin{array}{l}\text { participant } \\
1 \text { (Wave) }\end{array}$ & blog & $\begin{array}{l}\text { participant } 2 \\
\text { (Chat) }\end{array}$ & chat & $\begin{array}{l}\text { participant } 4 \\
\text { (Blog) }\end{array}$ & blog \\
\hline $\begin{array}{l}\text { participant } 1 \\
\text { (Wave) }\end{array}$ & blog & $\begin{array}{l}\text { participant } \\
3 \text { (Forum) }\end{array}$ & blog & $\begin{array}{l}\text { participant } 1 \\
\text { (Wave) }\end{array}$ & wave & $\begin{array}{l}\text { participant } 4 \\
\text { (Blog) }\end{array}$ & wiki \\
\hline $\begin{array}{l}\text { participant } 4 \\
\text { (Blog) }\end{array}$ & wave & $\begin{array}{l}\text { participant } \\
5 \text { (wiki) }\end{array}$ & wave & $\begin{array}{l}\text { participant } 4 \\
(B \log )\end{array}$ & wiki & $\begin{array}{l}\text { participant } 3 \\
\text { (Forum) }\end{array}$ & wave \\
\hline
\end{tabular}

Starting from the above ideas, the system can present the results of determining the points of convergence and divergence of views on a graphical form, through which it is easier for teachers to obtain important clear and detailed information. Figures 3-8 present statistics among pairs of utterances, on the top, horizontal dimension being the first utterance of the pair ("Part 1") and on the vertical dimension the second utterance ("Part 2"), which is a reply to the first one.

Figure 3 shows a table for the results of determining the points of convergence in the participant's series of utterances that resulted from the linking process between two similar threads. This indicates the convergence of ideas, which is revealed by their discussion to the same thread. Based on the numbers and colors that appear in figure, we can infer the analysis results. Thus, each color refers to the number of convergences between participants in their discussion threads. For example, the blue color refers to one convergence time, while the brown color refers to 5 convergence times between participants. Figure 3 allows knowing all the results of linking the individual participations for all participants in their discussion to the identical threads. For example, Participant1 agreed four times with 
Participant 2 in their discussion to the subject "chat". Also, there is no convergence in the discussion that occurred between Participant 1 and Participant 5 to the subject "blog". Besides, Fig. 3 reveals the number of convergence points among participants in their discussion to the threads.

Figure 4 shows a table for the obtained results from the analysis of the divergence in the points of views among participants, which resulted from the linking process between two different threads discussed among participants. This indicates there is a divergence in the ideas, as each participant discusses a thread different from the other. Based on the numbers and colors that appear in figure, we can inference the analysis results. Thus, each color refers to the number of divergences between participants in their discussion threads. For example, the red color refers to one divergence moment, while the brown color refers to 3 divergence times between participants. Figure 4 provides us with the results of linking the individual participations to all participants, who discussed various threads. For example, Participant 5 differed three times with Participant 2 in their discussion to the subjects (wiki and chat). As well, Fig. 4 indicates that there is no divergence in the points of views among Participant 2 and Participant 3.

Figures 5 and 6 provide the number of moments of convergence and divergence of views between all participants in detail, which help in giving teachers a general perception of the most identical and the most different opinions of the participants, and vice versa. Figure 5 shows the participants who are more convergent in the threads. They are Participant 5 in part 1 and Participant 2 in part 2. The participants who were less convergent in the threads are Participant 3 in part 1 and Participant 4 and 5 in part 2. In turn, Fig. 6 shows that the pair of users that have divergences in the Participant 5 ("Part 1"), and Participant 2 ("Part 2"), as the number of times for the divergence in their points of views along the chat registered eight times.

Figures 7 and 8 provide the results of the number of times of convergence and divergence between the threads along the chat. Throughout these results, the repetitions of the associative relations between threads can be figured out, in order to determine the most or less frequent threads that contained a divergence or convergence. Figure 7 shows the threads that have a most and less number of convergences in the chat, as the subject "chat" was the most convergent topic among participants, with nearly registered 33 times of convergence, where as Fig. 8 shows the number of times in which there was a divergence in discussing the thread "forum" as part 1 and the thread "chat" as part 2. The divergence between the threads was accounted for 8 times.

As a sum, by analyzing chat no. 3, the convergence of views in the students' discussion registered 99 times, whereas the divergence in the students' points of views registered 62 times. This gives a good indicator to the collaborative assessment in the transfer of knowledge, which indicates the student's high level of accepting the others' points of views and their discussion with each other without bias or selfish.

\section{Conclusions}

The proposed system seeks to provide a model for a technical tool capable of analyzing CSCL chats in a semi-automatic manner, in order to determine the points of convergence and divergence of views within the chat. Therefore, this system relies on Bakhtin's ideas and Trausan-Matu's polyphonic model to determine the most important threads that have been discussed within the chat. Then, the individual participations are analyzed for each participant by extracting all threads appeared in their discussions. After that, these threads 
are linked with each other, on the basis of linking two threads appeared sequentially or in an utterance of the chat and its reference. The result is associative relations among two threads for two participants. By these associative relations, the points of convergence and divergence can be identified in the discussion threads. For example, if the two threads that have been linked are alike, this indicates a convergence of ideas.

If the threads are different, this indicates a divergence in the ideas. In general, the system seeks to provide the results of chats analysis in the form of statistical graphics and tables, which easily allow determining the points of convergence and divergence in the points of views. The aim of determining these points in the educational chats is to help teachers in knowing the behavior of students in their discussion of the educational topics, as well as to assist teachers in determining the most important topics that were agreed upon by participants and vice versa. Besides, this helps in determining the most convergent and divergent participants in the points of views, which also helps teachers intervene when necessary in the students' discussions, in order to clarify the points of divergence. In addition, it helps developing educational strategies and plans that contribute to raising the level of performance of students in CSCL chats, in order to create educational chats that focus on the collaboration and participatory in the transfer of knowledge, through accepting and respecting the views of others without stress or selfishness.

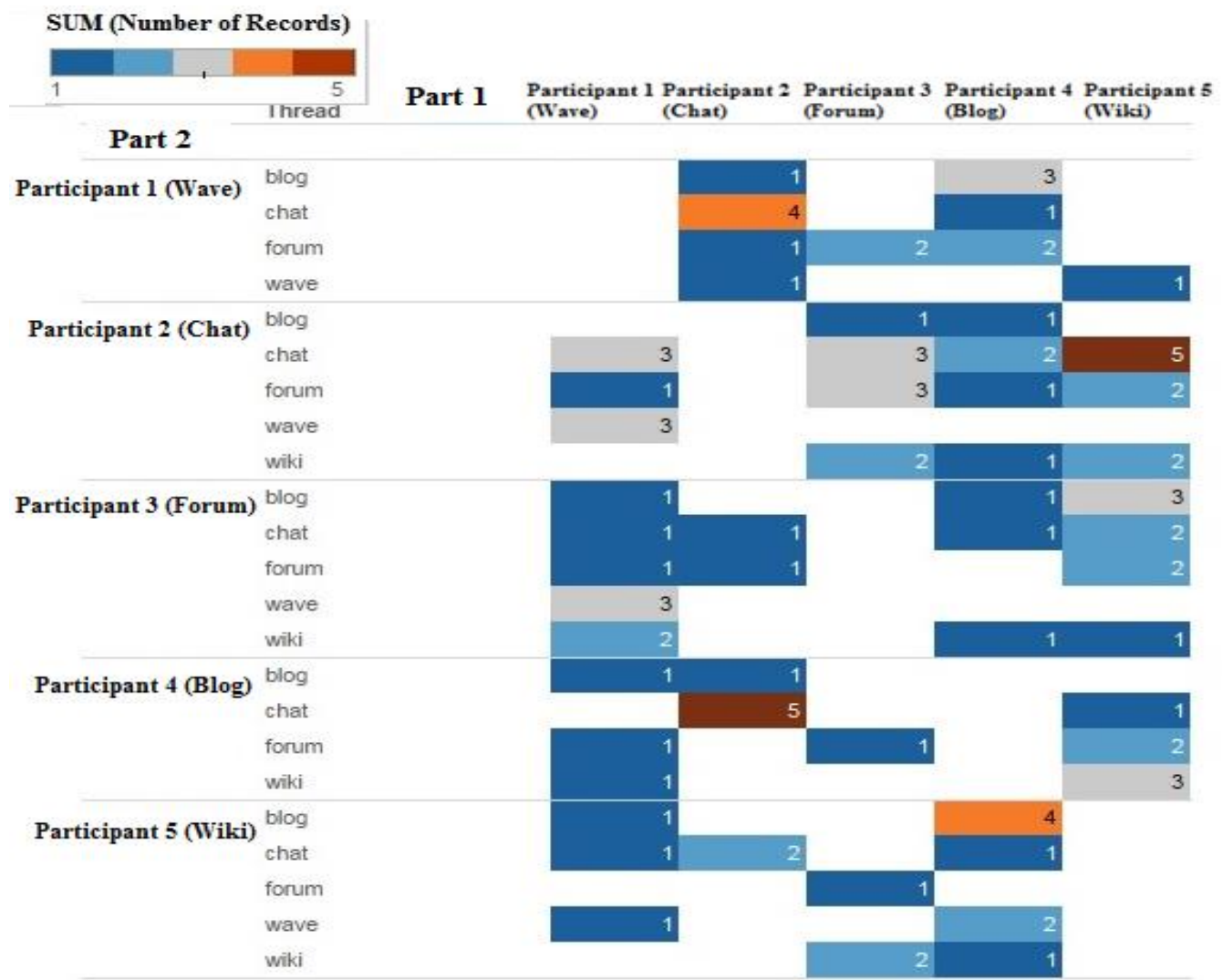

Fig. 3. The results of the analysis of convergences in the points of views among participants. 


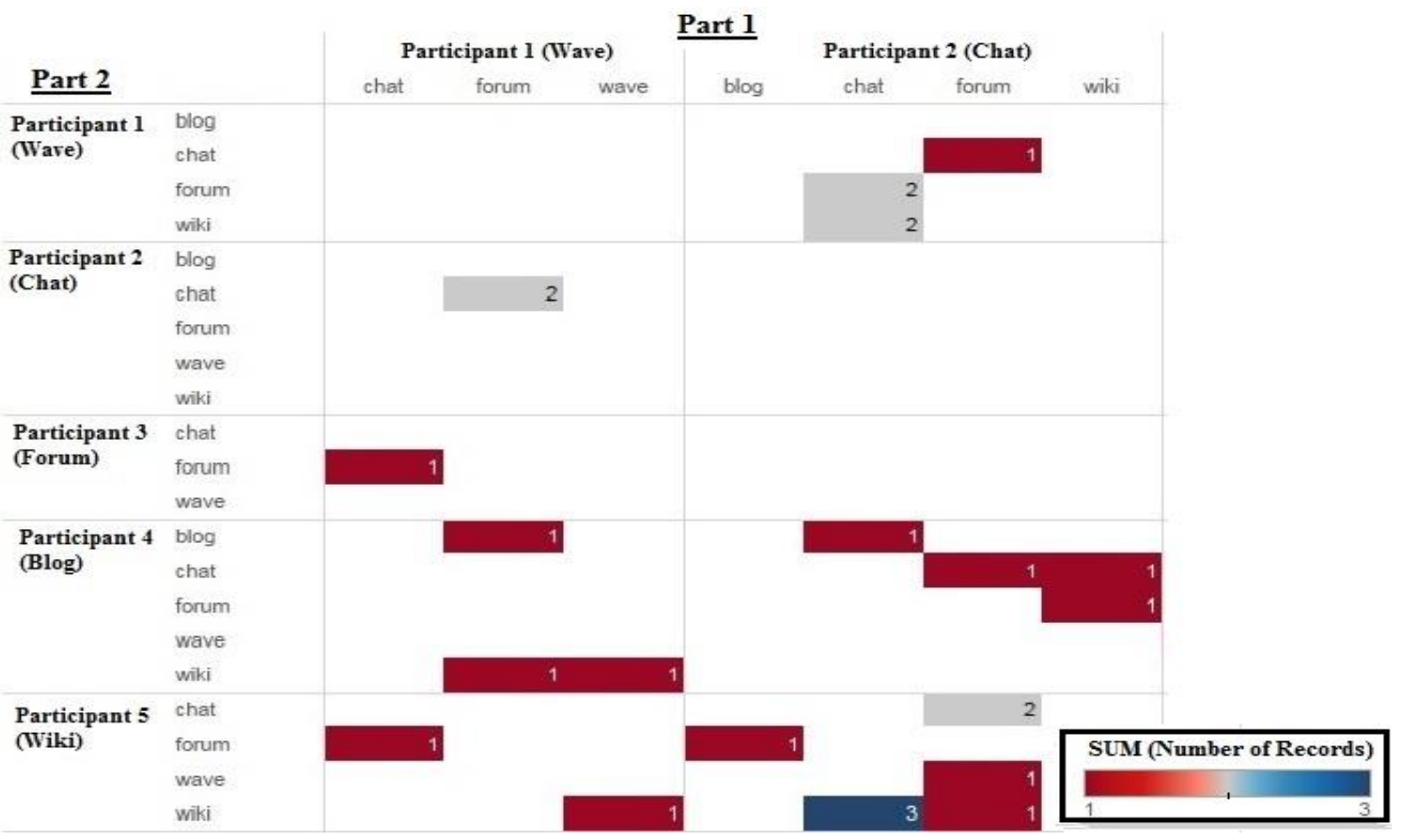

Fig. 4. The distributions of divergences in the points of views among participants.
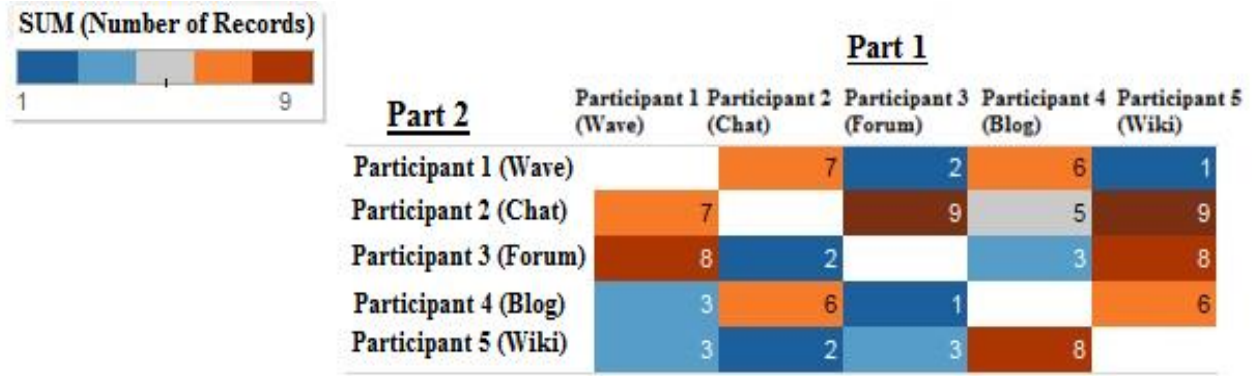

Fig. 5. The number of times of convergence of views between all participants.

\section{Part 1}
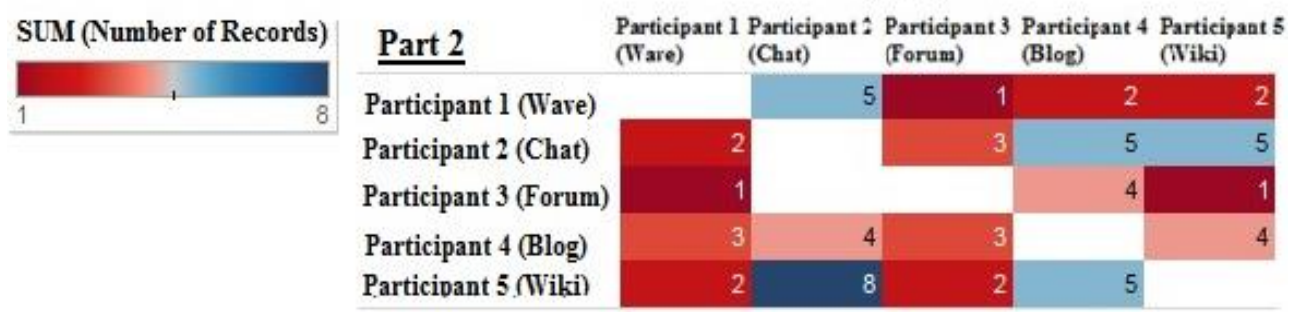

Fig. 6. The number of times of divergence of views between all participants. 


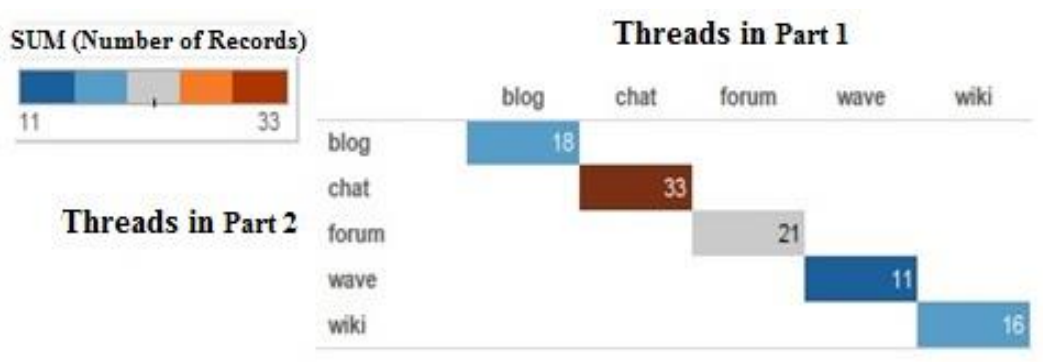

Fig. 7. The number of times of convergence of views between threads.

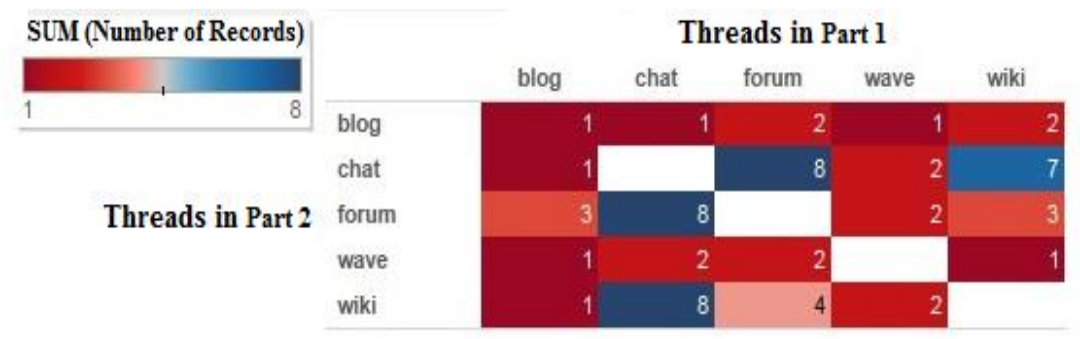

Fig. 8. The number of times of divergence of views between threads.

\section{References}

[ 1] Dascalu, M., Trausan-Matu, S. and Dessus, P. (2014). Validating the Automated Assessment of Participation and of Collaboration in Chat Conversations. In $\mathrm{S}$. Trausan-Matu, K.E. Boyer, M. Crosby and K. Panourgia (eds.), Proceedings of Intelligent Tutoring Systems Conference, Honolulu, USA, Springer, pp: 230-235.

[2] Stahl, G. (2006). Group Cognition. Computer Support for Building Collaborative Knowledge. Cambridge: MIT Press.

[3] Trausan-Matu, S. (2010). The Polyphonic Model of Hybrid and Collaborative Learning. In Wang, F.,L., Fong., J., Kwan, R.C., Handbook of Research on Hybrid Learning Models: Advanced Tools, Technologies, and Applications, Information Science Publishing, Hershey, New York, pp: 466-486.

[4] Trausan-Matu, S., Dascalu, M. and Rebedea, T. (2014). PolyCAFe - Automatic support for the analysis of CSCL chats. International Journal of ComputerSupported Collaborative Learning, 9(2): 127-156.

[5] Allaymoun, H.M. (2014). Analysis of Discourse Threading and Inter-animation in CSCL Chats, Conference on eLearning \& Software for Education, Issue 1. Romania.

[6] Stahl, G., Koschmann, T. and Suthers, D. (2006). Computer-supported collaborative learning: An historical perspective. In R. K. Sawyer (Ed.), Cambridge Handbook of the Learning Sciences. Cambridge, UK: Cambridge University, pp. 409-426.

[7] Marttunen, M. and Laurinen, L. (2007). Collaborative learning through chat discussions and argument diagrams in secondary school. Journal of Research on Technology in Education, 40 (1): 109-126.

[ 8] Roschelle, J. and Teasley, S. D. (1995). The construction of shared knowledge in collaborative problem solving. In C. O'Malley (Ed.), Computer Supported Collaborative Learning. Berlin: Springer, pp. 69-97.

[ 9] Allaymoun, H.M. and Trausan-Matu, S. (2016b). Analysis of the Altruistic Dimension of CSCL Chats, Proceedings of the 12th International Scientific Conference eLearning and software for Education, Bucharest. Romania.

[10] Bakhtin, M.M. (1984). Problems of Dostoevsky's Poetics, Theory and History of Literature Series, vol. 8, Minneapolis, (translated by C. Emerson).

[11] Bakhtin, M.M. (1986). Speech Genres \& Other Late Essays, University of Texas Press, Austin.

[12] Bakhtin, M.M. (1993). Problems of Dostoevsky's Poetics. University of Minnesota Press, Minneapolis.

[13] Trausan-Matu, S., Stahl, G. and Zemel, A. (2005). Polyphonic Inter-animation in Collaborative Problem Solving Chats, Research Report, Drexel University, Philadelphia.

[ 14] Allaymoun, H.M. and Trausan-Matu, S. (2016) .Analysis of Collaboration in CSCL Chat Using Rhetorical Schemas, Proceedings of the 19th IEEE International Conference on Information and Communication Systems, Irbid, Jordan.

[15] Allaymoun, H.M. and Trausan-Matu, S. (2015). Rhetorical Structure Analysis for Assessing Collaborative Processes in CSCL, Proceedings of the 19th IEEE International Conference on System Theory, 
Control and Computing, ICSTCC2015, Cheile Gradistei, Romania, pp: 123-127.

[ 16] Runco, M. A. (1990) The divergent thinking of young children: Implications of the research. Gifted Child Today, 13: 37-39.

[17] Runco, M. A. and Albert, B. S. (1989). Independence and the creative potential of gifted and exceptionally gifted boys. Journal of Youth and Adolescence, 18: 221223.

[18] Puccio, G. J. (1998). Letters from the field. Roeper Review, 21: 85-86.

[ 19] Yang, Li-chiung. (2013). Prosodic Convergence, Divergence, and Feedback: Coherence and Meaning in Conversation. Proceedings of the 27th Pacific Asia Conference on Language, Information, and Computation (PACLIC-27), pp: 85-91.

[ 20] Dascalu, M., Trausan-Matu, S., Dessus, P. and McNamara, D.S. (2015). Discourse cohesion: A signature of collaboration. In 5th Int. Learning Analytics \& Knowledge Conf. (LAK'15), pp: 350-354. Poughkeepsie, NY: ACM.

[21] Chiru, C., Cojocaru, V., Trausan-Matu, S., Rebedea, T. and Mihaila, D. (2011). Repetition and Rhythmicity Based Assessment Model for Chat Conversations. in: Marzena Kryszkiewicz, Henryk Rybinski, Andrzej Skowron, Zbigniew W. Ras (Eds.): Foundations of Intelligent Systems - 19th International Symposium, ISMIS 2011, Warsaw, Poland, June 28-30, 2011. Lecture Notes in Computer Science 6804 Springer 2011, pp: 513-522.

[22] Denisleam (Molomer), S. and Trausan-Matu, S. (2016). Automatic analysis of pauses in collaborative learning chats, The 12th International Scientific Conference eLearning and Software for Education Bucharest. 
تحديد نقاط التقارب والتباعد في التعليم التعاوني المعتمد على الحاسوب

\section{محمد حامد الليمون'، و ستيفن تريسان ماتيو'}

'جامعة أما الدولية البحرين، المنامة، البحرين، و بقفم علوم الحاسبات، جامعة بوليتكنيكا في بوخارت،

$$
\text { بوخارست، رومانيا }
$$

alkarak1@yahoo.com

الدستخلص. التعليم التعاوني المتتمد على الحاسوب هو واحد من أهم الإنجازات المهمة لتحسين

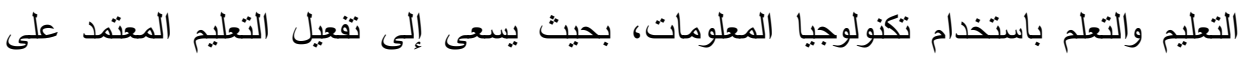

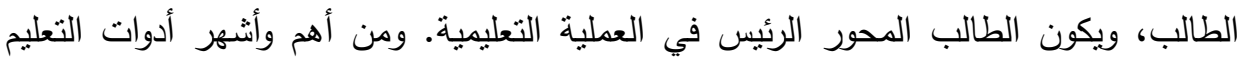
التعاوني المعتمد على الحاسوب، هي المستخدمة في نقل المعرفة وتبادل المعلومات المحادئة المعادة.

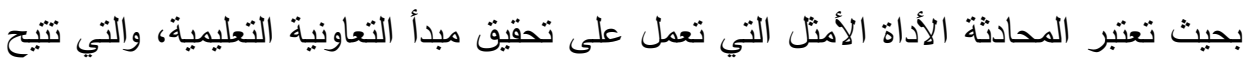

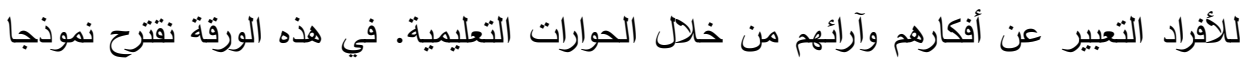

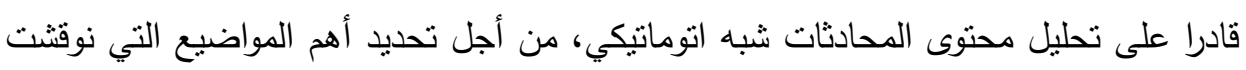

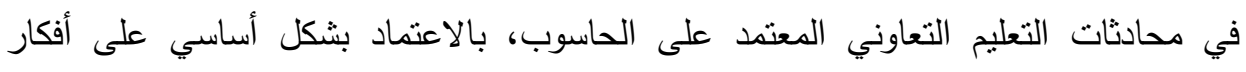

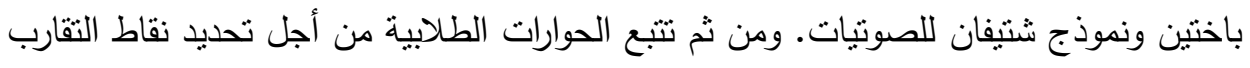

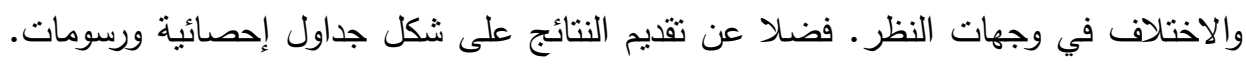

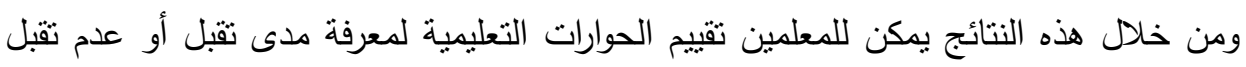

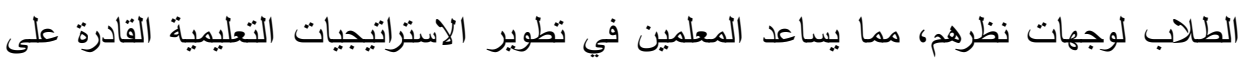
الوصول إلى حوار تعليمي نعاوني خالٍ من التثدد والأنانية. الكلمات الدفتاحية: النعليم التعاوني الدعند على الحاسوب، تثتب المحادثة، التقارب، المشاركة الفردية، معالجة اللغة الطبيعية. 